\title{
PERSPECTIVE
}

\section{Connecting the eye to the brain: the molecular basis of ganglion cell axon guidance}

\section{S F Oster, D W Sretavan}

Br J Ophthalmol 2003;87:639-645

In the past several years, a great deal has been learnt about the molecular basis through which specific neural pathways in the visual system are established during embryonic development. This review provides a framework for understanding the principles of retinal ganglion cell axon guidance, and introduces some of the families of axon guidance molecules involved. In addition, the potential relevance of retinal axon guidance to human visual developmental disorders, and to retinal axon regeneration, is discussed.

See end of article for authors' affiliations ..............................

Correspondence to: David W Sretavan, MD, PhD, Department of Ophthalmology, K107, Box 0730, University of California San Francisco, 10 Kirkham Street, San Francisco, CA 94143, USA; dws@itsa.ucsf.edu

Accepted for publication 14 July 2002
W iring the human brain is one of nature's greatest feats, and one of its most daunting tasks. Neurons numbering in the billions must be specifically connected to one another to assemble functioning neural circuits. The basic framework of neuronal connectivity is built during fetal development in a process called axon pathfinding. During pathfinding, the axons of developing neurons navigate long distances along specific pathways to reach their appropriate targets. The characterisation of the molecules in the developing brain environment that guide axons, as well as the receptors and signalling cascades through which guidance molecules exert their influence, form the central areas of investigation in the field of axon guidance.

One of the best studied models of axon guidance is the developing retinal ganglion cell (RGC) and its axon. Recent work has begun to shed light on the molecular mechanisms that govern RGC axon guidance during optic nerve development, the formation of the optic chiasm, and the establishment of retinotopic maps in visual targets such as the superior colliculus. Our goal in this review is to discuss a number of the pathfinding tasks that developing RGC axons must accomplish. In doing so, we will provide examples of how guidance molecules steer RGC axons to illustrate fundamental principles of axon pathfinding. In addition, we will highlight aspects of RGC axon guidance that have potential relevance to visual developmental disorders, and discuss how lessons of axon guidance may be applied towards a better understanding of axon regeneration in the visual system.

\section{THE AXON GROWTH CONE AS AN EXPLORATORY APPARATUS}

During pathfinding, axons elaborate specialised structures at their tips called growth cones through which they sense and respond to the environment (see Fig 1). The growth cone is a fan-shaped motile structure with finger-like filopodia, and is constructed of actin filaments extending from a central microtubule core. ${ }^{1}$ As a growth cone extends in the embryonic environment, receptor molecules on its surface interact with guidance molecules displayed in the extracellular matrix or on the surfaces of surrounding cells. Upon activation of these receptors by guidance molecules, intracellular signalling cascades are triggered which eventually feed into pathways altering the assembly of cytoskeletal components such as actin and tubulin. Signalling cascades causing a net addition of cytoskeletal components are thought to lead to growth cone advance, while net disassembly may lead to axon retraction. Asymmetric signalling on one side of the growth cone is thought to lead to turning and change in the direction of growth..$^{1-3}$ In the past several years, as researchers identified significant numbers of guidance molecules and begin to understand how particular combinations are used for specific pathfinding tasks, the rough outlines of how the visual system is assembled is beginning to emerge.

\section{BASIC BUILDING BLOCKS-GROWTH CONE ATTRACTION VERSUS REPULSION}

Among the earliest axon guidance molecules identified were extracellular matrix molecules such as laminin and fibronectin that promote axon growth. Analysis of the protein domain structure of these and other subsequently identified families of guidance molecules showed that guidance molecules in general all contain a number of common domain motifs such as immunoglobin-like repeats, EGF repeats, and fibronectin type III domains. Each family of guidance molecules is, however, also defined by its own distinctive domain (see reviews by TessierLavigne and Goodman ${ }^{4}$ and Yu and Bargmann ${ }^{5}$ ). In addition to guidance molecules that promote axon outgrowth, an important contribution to our understanding of axon pathfinding was the discovery that a substantial number of guidance proteins control axons by inhibiting their ability to extend. Given that the nervous system is able to both encourage and inhibit axon growth, it would seem that one simple strategy for axon guidance is to use arrays of growth promoting and inhibitory guidance cues to steer developing axons along specific pathways to their targets. Indeed, as illustrated in the following examples, there are instances of RGC axon guidance that seem to reflect this strategy. 


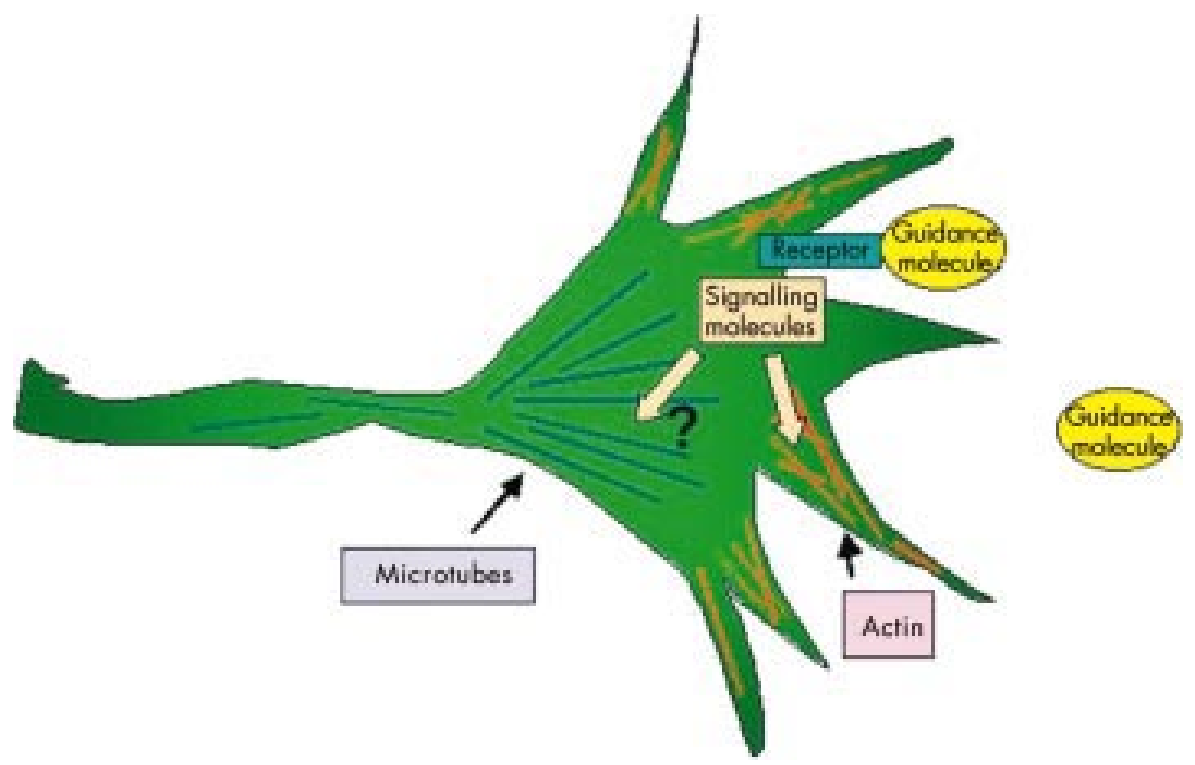

Figure 1 The growth cone. Extracellular guidance molecules bind surface receptors on the growth cone. In turn, these receptors activate signalling cascades that ultimately influence growth cone cytoskeletal components controlling morphology and motility. Signalling cascades are known to affect the actin cytoskeleton. It is not clear whether there are also direct influences on growth cone microtubule assembly during axon guidance.

\section{GROWTH PROMOTION AND AXON FASCICULATION}

The first major pathfinding task for a newly born RGC is to extend an axon towards the optic nerve head. During development, ganglion cells are born in a central to peripheral gradient such that the oldest RGCs are closest to the optic disc and the younger RGCs are in more peripheral retina. Newly formed RGC axons are in contact with axons of older RGCs and travel along, or fasciculate with, these neighbouring axons to reach the optic nerve head. This fasciculation appears to be due to growth promoting molecules such as $\mathrm{Ll}$ on the RGC axons themselves. $\mathrm{Ll}$ is a member of the immunoglobulin family of cell adhesion molecules, ${ }^{6}$ and functions in a homophilic manner. Homophilic binding means that an Ll molecule on a given axon binds an $\mathrm{Ll}$ molecule on an adjacent axon. It is thought that such Ll homophilic interactions encourage retinal axons to grow in bundles, or fascicles, within the retina on their way to the optic disc. This model is supported by the finding that experimental blockade of $\mathrm{Ll}$ function, or the function of related Ig guidance molecules, causes RGC axons to wander in the retina instead of growing directly to the optic disc. ${ }^{78}$ Thus, RGC axon pathfinding to the optic disc appears to involve the ability of retinal growth cones to follow a trail of attractive axon guidance molecules.

\section{Attraction from a distance}

Along with guidance molecules such as LI that are displayed on surfaces of cells or other axons, the nervous system also uses secreted proteins to attract axons. These secreted attractants add a degree of versatility to pathfinding because they can diffuse away from their source to influence growth cones at a distance. Netrin- 1 was the first secreted attractant identified in vertebrates, and was initially characterised as an important guidance molecule during development of the spinal commissural axons. ${ }^{9-11}$ The floorplate, which forms the ventral midline of the developing spinal cord, secretes netrin molecules that can diffuse away to form a gradient. The axons of commissural neurons in dorsal spinal cord find their way ventrally to the midline by following this increasing netrin gradient. In the visual system, several lines of evidence have shown that netrin-1 plays a critical part in RGC axon exit from the retina into the developing optic nerve. ${ }^{12}$ Firstly, netrin-1 protein is expressed by neuroepithelial cells at the developing optic nerve head which are in close contact with RGC axons. Secondly, RGC axons in vitro respond to netrin- 1 as an attractive guidance molecule. Lastly, mice with a targeted deletion of the netrin-1 gene exhibit pathfinding errors at the optic disc where RGC axons fail to exit into the optic nerve and instead grow inappropriately into the other side of the retina (see Fig 2 ). As a result of this aberrant pathfinding, these mice exhibit optic nerve hypoplasia. ${ }^{12}$

\section{USING INHIBITORY GUIDANCE IN THE RETINA}

The discussion thus far has focused on guidance attraction either as a result of RGC growth cones contacting cell or axon surfaces displaying growth promoting cues or responding to diffusible molecules secreted at a distance. However, RGC axon pathfinding in the retina also uses inhibitory guidance molecules. After RGCs are born, what ensures that their axons head correctly towards the optic nerve head instead of growing towards the peripheral retina? Although an explanation involving intrinsic RGC properties that properly orient initial axon outgrowth is possible, studies in rodents have provided evidence for an active inhibitory mechanism preventing RGC axons from heading incorrectly towards the peripheral retina. This mechanism appears to involve a ring of chondroitin sulphate proteoglycan in the peripheral retina adjacent to the youngest RGCs (see Fig 3). Chondroitin sulphate is found in the extracellular matrix, and has been shown to inhibit RGC axon growth in vitro. ${ }^{13}{ }^{14}$ Enzymatic breakdown of chondroitin sulphate during retinal development resulted in RGC axons with abnormal trajectories in the peripheral retina. ${ }^{13}$ These findings suggest that inhibition helps send RGC axons in the correct direction towards the optic disc at the very start of their journey.

\section{INHIBITORY GUARDRAILS DURING OPTIC CHIASM DEVELOPMENT}

Growth cone inhibition is also important once RGC axons have left the retina. The slit proteins are a family of inhibitory axon guidance molecules that were originally discovered to have a guidance role in the Drosophila midline and longitudinal tracts. ${ }^{15}{ }^{16}$ In mammalian development, slits have been implicated in olfactory system guidance, neural migration, and axon branching ${ }^{17-19}$ (for a slit review see Brose and Tessier-Lavigne $\left.{ }^{20}\right)$. Recent work has demonstrated that slit proteins govern where RGC axons form the optic chiasm on the ventral surface of the developing hypothalamus. ${ }^{21}$ Slits are known to inhibit RGC axons in vitro, ${ }^{22-24}$ and are normally expressed in regions both anterior and posterior to the developing optic chiasm. In mice deficient in slits, some RGC axons form a secondary optic chiasm anterior to the normally situated optic chiasm. ${ }^{21}$ The region into which the chiasm was 

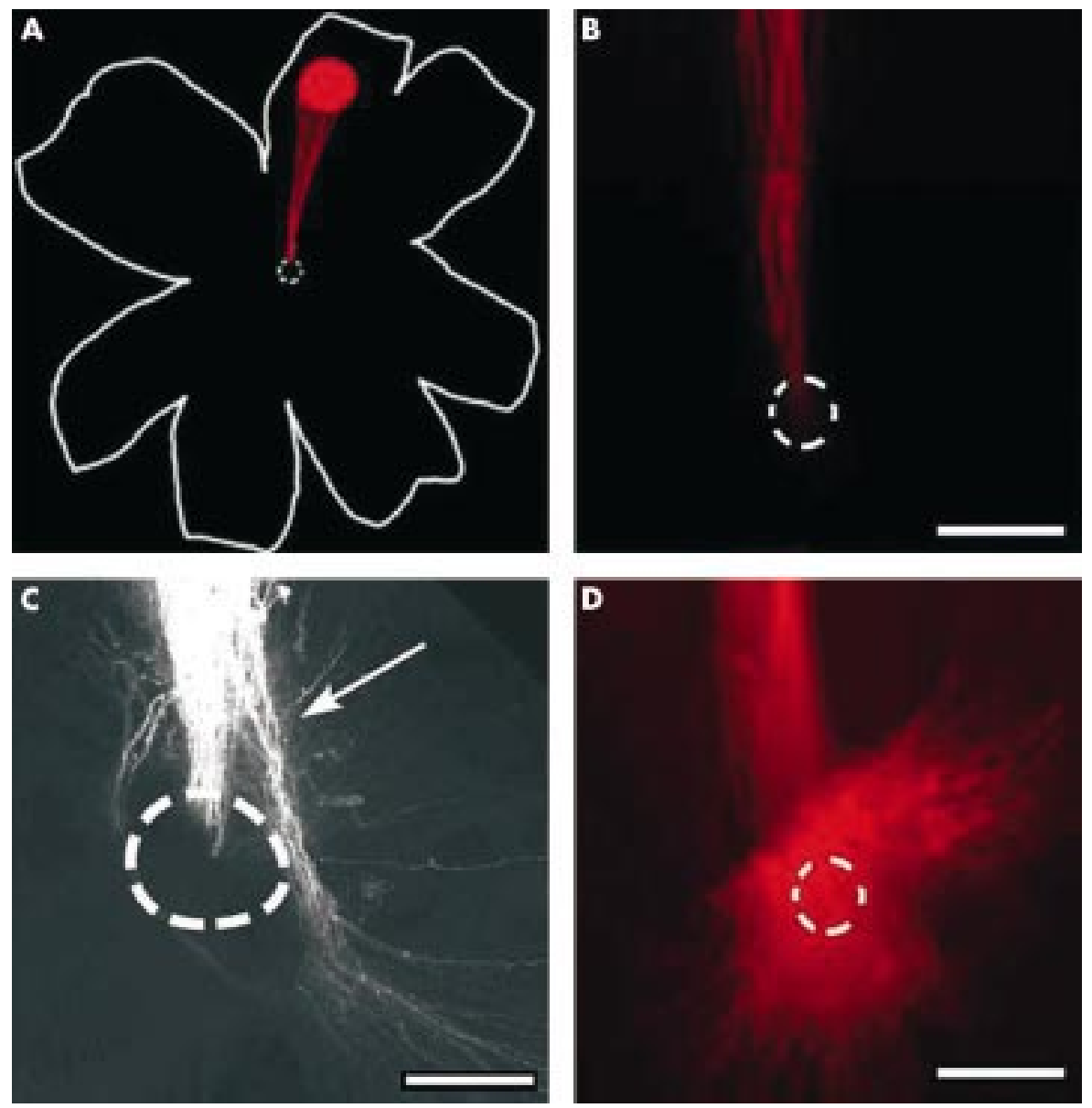

Figure 2 Axon pathfinding to the optic disc. (A) A crystal of Dil placed in the periphery of a flat mounted retina labels RGC axons projecting towards the optic disc (broken circle). (B) In a wild type retina, RGC axons travel directly to the optic disc and exit the retina. (C) In EphB2, EphB3 double null mutant retinas, axon fascicles split off from the main group, fail to exit at the optic disc, and grow

aberrantly into the opposite side of the retina. (D) In netrin deficient retinas, many axons at the optic disc splay out into the surrounding retina instead of passing through the disc and into the optic nerve. All scale bars are $100 \mu \mathrm{m}$. (Permission to reproduce parts (A), (B), and (D) from Deiner et $a^{12}$ was granted by Elsevier Science through the rights manager, Helen Wilson, on 28 June 2002; and to reproduce part (C) from Birgbaver et $a^{\beta 9}$ was granted by the Company of Biologists Ltd through the permissions administrator, Jen Ostler, on 27 June 2002.) shifted normally expresses slits, suggesting that slit inhibition forms a barricade to properly channel RGC axons at the chiasm (see Fig 3). However, since not all RGC axons are affected by the slit deficiency, other guidance cues must also play a part in governing RGC axon pathways at the developing optic chiasm.

\section{Growth cone repulsion at a distance}

Just as growth promoting molecules exist as cell attached and secreted proteins, inhibitory guidance molecules can also exist as cell attached or diffusible repellents. The first diffusible inhibitory guidance molecule identified belonged to the semaphorin family (for semaphorin reviews see Nakamura et $a l^{25}$ and Raper $\left.^{26}\right)$. Now called Sema3A, this protein was identified by its ability to "collapse" growth cones in vitro. ${ }^{27}$ Collapse has become a hallmark of in vitro inhibition, and occurs when axons treated with an inhibitory molecule undergo actin depolymerisation, lose their filopodia and fan-shaped structure leaving just a thin tip. ${ }^{27}$ A role for semaphorins in RGC axon guidance has yet to be clearly established. However, there is recent evidence that Sema3A collapses RGC axons from the frog Xenopus laevis in vitro, ${ }^{28}$ although it is not known where Sema3A is expressed in the developing visual system. Studies have also identified the presence of a transmembrane semaphorin (Sema VI) in the mammalian retina. ${ }^{29}$ However, since semaphorins have diverse roles in development including control of neural migration, ${ }^{30}$ it is not clear whether the semaphorin VI influences RGC axon guidance or other aspects of retinal development. While the role of semaphorins in the development of central retinal pathways remains to be determined, it is of note that Sema3A is expressed in developing cranial tissues. Mice deficient in Sema3A exhibit cranial nerve axon guidance errors resulting in abnormal innervation patterns of the facial and trigeminal nerves. ${ }^{31}$

\section{Mapping through gradients}

The previous examples have illustrated how the visual system uses individual guidance molecules to provide simple forms of growth cone attraction or inhibition. It is clear however that more sophisticated strategies such as graded inhibition are also employed. The use of gradients of guidance molecules is best illustrated by the formation of the retinotopic map in the superior colliculus. The characteristic feature of the retinotopic map is that axons of neighbouring RGCs project to neighbouring sites in CNS targets to faithfully recreate a retinal map of visual space. The molecular mechanism of mapping represents an intriguing problem since the targeting of each axon must be coded by slightly different information from its neighbours for proper alignment. Rather than assigning a distinct guidance receptor to each axon, and an individual guidance molecule to each target cell, the nervous system uses gradient mapping to solve the problem.

Early insight came when researchers discovered that given a choice in vitro, RGC axons from the chick temporal retina avoided growing on cell membranes harvested from the posterior optic tectum (avian homologue of the superior colliculus), and that this avoidance was due to a repellent molecule present in posterior tectal membranes. ${ }^{32}$ The repellent turned out to be one of a large group of protein ligands now collectively called the ephrins (for a general Eph/ephrin review see O'Leary and Wilkinson ${ }^{33}$ ). Subsequent work in both chicks and mice revealed that specific ephrins are expressed in an anterior-posterior gradient in the colliculus, while within the retina, a nasal-temporal gradient of the corresponding Eph receptors are expressed by RGCs (reviewed in Wilkinson $\left.{ }^{34}\right)$. Owing to the inhibitory action of the ephrins, axons from the temporal retina carrying a relatively large number of Eph receptors avoid posterior colliculus where 


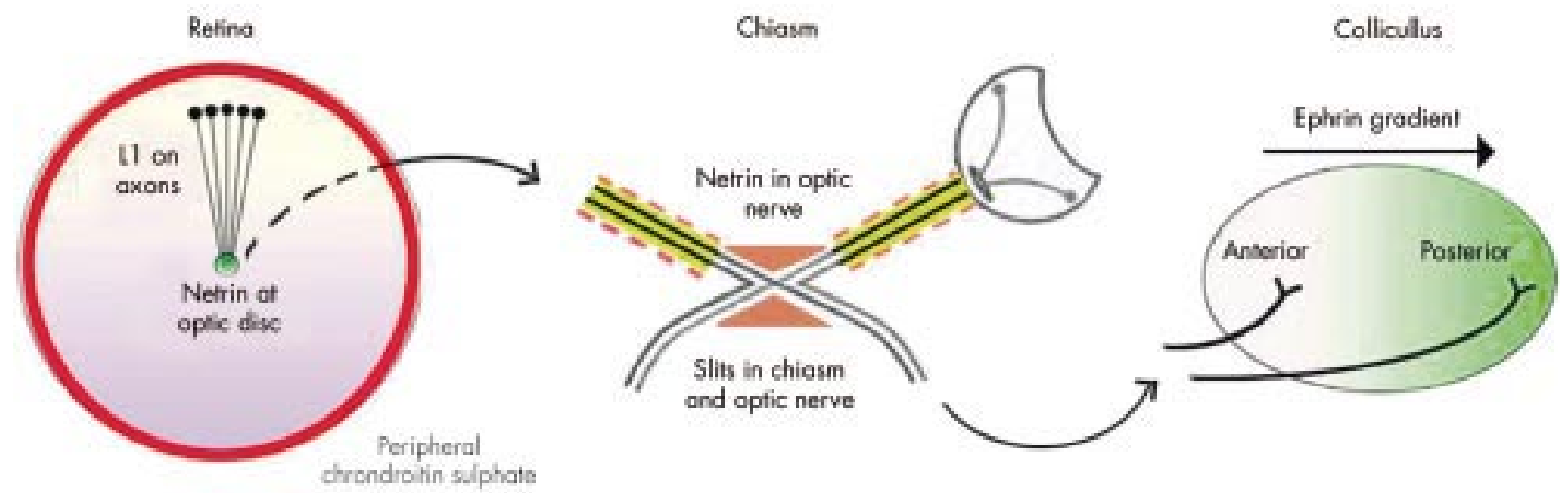

Figure 3 Mechanisms of RGC axon guidance in the vertebrate visual system. In the retina, axons are repelled from the periphery by chondroitin sulphate. En route to the optic disc, RGC axons fasciculate due to L1 expression and an Eph inhibitory gradient. At the optic disc, RGC axons exit into the optic nerve using a mechanism based on netrin mediated attraction. Within the optic nerves, RGC axons are kept within the pathway, possibly by inhibitory slit protein. Slits also contribute to positioning the optic chiasm by creating zones of inhibition. Finally with the superior colliculus, RGC axons map to specific target positions by responding to gradients of inhibitory ephrin molecules. Axons from temporal retina, which express high levels of Eph receptors, map to anterior colliculus, which express low levels of the inhibitory ephrin ligand.

ephrins are highly expressed. Axons from the progressively more nasal retina, on the other hand, carry fewer Eph receptors that are thus capable of mapping to more posterior sites in the target. The graded expression of Eph receptors, on different RGC axons and gradients of inhibitory guidance molecules, assists the visual system in generating a retinotopic mapping in the colliculus. Additional work has suggested that Eph/ephrin gradients may also contribute to RGC topographic target recognition in other visual targets such as the lateral geniculate nucleus. ${ }^{35}$ The use of inhibitory gradients to sort RGC axons enormously amplifies the amount of information carried by a small set of guidance molecule-receptor pairs.

\section{Bifunctionality and reverse signalling}

So far in this review, the discussion has categorised guidance molecules into those that promote axon outgrowth and those that exert inhibitory effects on growth cones. It is now known that this distinction is not always correct, and that, at times, the same axon guidance molecule can act as either an attractant or a repellent. Bifunctionality not only offers increased flexibility during axon guidance, but also maximises the amount of guidance information that a single molecule can provide. Evidence in mammals for the ability of a single guidance molecule to both attract and repel axons has come from studies showing that netrin-1, known to promote growth from spinal axons and RGCs, actually repels the axons of trochlear motor neurons. ${ }^{36}$ These experiments corroborated earlier evidence from invertebrates that a single Netrin source could attract some neurons and repel others. ${ }^{37}$ Bifunctional guidance information blurs the distinction between attractive and repulsive guidance as the function of a given guidance molecule depends on the axon population being affected.

Another example of the nervous system maximising guidance information resulting from ligand/receptor interactions can be found in the Eph/ephrin family of guidance molecules. It is known that ephrins normally bind to Eph proteins that serve as receptors in RGC axon mapping in the superior colliculus. However, a number of studies have also shown that Eph proteins can additionally act as ligands and trigger signalling events in cells expressing ephrins. First described in biochemical studies, ${ }^{38}$ this reverse flow of information from Eph through ephrin molecules has been shown to have an important role in RGC axon navigation within the retina to the optic disc. Although Ig family molecules such as Ll mediate retinal axon fasiculation during growth towards the optic nerve head, Ll by itself is not enough. The visual system also exposes retinal axons approaching the optic nerve head to an inhibitory gradient of EphB proteins in order to maintain tight axon fasciculation ${ }^{39} 40$ (see Fig 2). Elimination of EphB proteins, which in this case are functioning as guidance molecules, results in retinal axon defasciculation with the affected retinal axons bypassing the optic nerve head exit point. ${ }^{39} 40$

\section{Integration at the growth cone}

As expression patterns of more guidance molecules in the developing brain were characterised, it became clear that the nervous system does not simply use a serial non-overlapping sequence of guidance molecules to steer axons. Instead, growth promoting molecules are often found in regions overlapping with inhibitory guidance molecules. The simplest way for a growth cone to combine information presented simultaneously by multiple guidance cues is to sum all the guidance forces. This model predicts that growth cones are influenced by the net effect of the total attractive and repulsive forces. Some evidence for a summation model comes from genetic studies in Drosophilia. Experimental alterations in the expression levels of attractive netrins versus inhibitory semaphorins in individual muscle cells resulted in predictable behaviour of the innervating motor axon growth cone. For example, ramping up semaphorin mediated inhibition in the muscles, which repelled motor neuron axons, could be counterbalanced by also raising the levels of netrin mediated attraction in the muscles. ${ }^{41}$ In this system, it appears that motor axons find their appropriate muscle targets based on a proper balance of attraction and repulsion.

\section{MODULATION OF RESPONSES}

In addition to the summation model described above, evidence suggests that the nervous system can also combine guidance information in a less predictable fashion. For example, RGC axons from the frog Xenopus interpret netrin-1 to be an attractive guidance molecule, and they will grow towards a netrin-1 source in vitro. ${ }^{42}$ However, if RGC axons are also simultaneously exposed to laminin, a molecule that normally promotes growth, an inhibitory response is triggered. ${ }^{43}$ This surprising finding demonstrates that a growth promoting substrate and a diffusible attractant can combine into an inhibitory force. In Xenopus, like in the mouse retina, the diffusible attractant netrin-l is present at the optic nerve head, and probably also governs retinal axon growth into the optic nerve. Given that laminin is present in the region of the mammalian optic nerve head, the results suggest that in normal development, as RGC axons simultaneously encounter both laminin and netrin-1, inhibition drives axons away from 
the laminin rich retinal surface through the optic nerve head. In this situation, the growth cone's response to netrin is switched by the presence or absence of laminin. This mode of action allows the nervous system to modulate the effects of a guidance molecule on an axon by adding or subtracting a second cue.

\section{CELL SIGNALLING AND SWITCHING BETWEEN ATTRACTION AND INHIBITION}

One mechanism that could explain how growth cones exhibit varying responses to the same guidance molecule under different circumstances involves cyclic nucleotide mediated intracellular signalling. Experiments have indicated that attraction and repulsion are determined downstream of the guidance receptor and, in fact, a single axon can be made to grow towards or away from a guidance molecule source by manipulating only the cyclic nucleotides in the growth cone. $^{2342}$ This finding made very clear that the attractive or inhibitory effects of guidance molecules and their receptors are not inherent to the proteins at the cell surface, but instead are a result of multiple interacting intracellular signalling cascades. These interacting signalling cascades present a mechanism for the integration of multiple guidance messages, and could explain how a growth cone changes its response to a given guidance molecule at different points in a pathway. A better understanding of the intracellular events controlled by various ligand-receptor pairs will provide insight into how guidance molecules combine to steer growth cones in vivo.

\section{RECEPTOR SILENCING AND HIERARCHY OF GUIDANCE RESPONSE}

An important question in axon guidance is how axons that have grown into an attractive area can ultimately leave and continue on the next segment of their pathfinding journey. While several possibilities exist, there is evidence that exposure to a new guidance molecule can silence the effects of guidance forces that the growth cone was following previously. This silencing idea represents a novel model for how axons integrate multiple guidance forces. As described earlier in this review, a netrin-1 gradient produced by the floorplate attracts spinal commissural axons to the ventral midline. Interestingly, the floorplate also produces inhibitory slits. It appears that commissural axons approaching the floorplate are attracted by netrins and ignore the slit protein. However, once these same axons cross the ventral midline at the floorplate, they are no longer affected by netrin-1 and instead are repelled by slits. The underlying mechanism is that the slit receptor itself, which only becomes available after midline contact, mediates not only the slit based repulsion but also binds directly to, and silences, the netrin receptor. ${ }^{44}$ This scenario allows the axons to be drawn towards the netrin rich floorplate, and then repelled by slit from the floorplate so the axons do not linger at or recross the midline..$^{45}$ Using receptor silencing in this fashion, the nervous system can potentially control which of many available guidance factors influence the growth cone at different points along an axon's journey. Currently it is not known whether receptor silencing also works to mediate RGC axon pathfinding. However, one segment of the retinal pathways where this mechanism may come into play is the optic nerve, where both netrin and slit are known to be present. A form of receptor silencing may be required for RGC axons to leave netrin attraction in the optic nerve and enter the chiasm midline region known to lack netrin. $^{12}$

\section{AXON GUIDANCE IN THE HUMAN VISUAL SYSTEM}

Almost all of the studies discussed above were performed in the developing visual systems of lower vertebrates or rodents. Naturally, one question is how much of what we have learned about retinal axon guidance from these species can be applied towards understanding how the human visual system is assembled. Some insight can be obtained by considering the fact that the molecular basis of growth cone guidance is highly conserved throughout evolution. For example, homologues of many of the axon guidance molecules discussed here, such as netrins, slit, and semaphorins, have been identified in invertebrates such as the fruit fly Drosophilia and the nematode $C$ elegans, where they also participate in axon pathfinding during neural development. ${ }^{15}{ }^{37} 46-48$ Human homologues of netrins, slits, semaphorins, and ephrins have also been identified, ${ }^{46}{ }^{49}$ but as yet, little is known about their patterns of expression or function during human development. However, it seems highly likely that these same gene families, and similar axon guidance principles, contribute to patterning the human visual system. A list of molecules contributing to axon guidance is given in Table 1 .

\section{DEVELOPMENTAL DISORDERS}

It is of note that the elimination of specific axon guidance molecules during development of the mouse nervous system have resulted in phenotypes that bear a striking resemblance to CNS abnormalities found in some human syndromes. Several examples come from axon guidance studies within the retina. For instance, the loss of netrin- 1 at the optic disc causes RGC axons to fail to exit the retina, and leads to optic nerve hypoplasia. ${ }^{12}$ Optic nerve hypoplasia is an important cause of childhood visual disability, and a number of potential aetiologies have been proposed including abnormal RGC neurogenesis, or inappropriate RGC cell death due to defects in target derived trophic support. The examination of netrin-l function in mouse visual development suggests that an additional potential mechanism is defects in genes encoding retinal axon guidance molecules. In addition to defects in optic nerve formation, the lack of netrin- 1 function during development also results in abnormalities in other parts of the CNS. These include agenesis of the corpus callosum, and a number of cell migration and axon guidance defects in the hypothalamus. ${ }^{50}$ In humans, the triad of optic nerve hypoplasia, abnormal corpus callosum formation, and pituitary dysfunction is found in the syndrome septo-optic dysplasia. ${ }^{51}$

Mice lacking Eph B guidance proteins also exhibit retinal axon guidance defects. RGC axons in these mice stray away from normally tight fascicles and miss the optic disc exit point ${ }^{40}$ Of note, these guidance defects are found specifically in axons originating from the dorsal, or superior, part of the retina. ${ }^{40}$ In humans, a similar restriction of an anatomical defect to superior retina is present in patients with superior segmental nerve hypoplasia patients. ${ }^{52}$ One speculation is that the pathogenesis of superior segmental optic nerve hypoplasia shares similarities with the developmental mechanisms controlling expression of axon guidance molecules in the dorsal-ventral retinal axis.

\section{REGENERATION IN THE VISUAL SYSTEM}

The remarkable capacity for growth, and specific wiring, during development is not present in the adult visual system. Adult retinal axons, after damage through disease or trauma, are incapable of regenerating and re-establishing functional circuitry. As a consequence, injury to the visual system, like damage elsewhere to the adult CNS, results in permanent functional impairment. Given the debilitating effects of CNS axon injury, substantial effort has been undertaken to identify the reasons for the failure of axon regeneration in the injured brain. Studies show that adult CNS neurons, including RGCs, retain the ability to regrow, but appear to be prevented from doing so by inhibitory proteins in their environment. Identified inhibitory proteins include CNS myelin proteins such as Nogo (reviewed in Brittis and Flanagan ${ }^{53}$ ) and myelin associated glycoprotein (MAG), ${ }^{54}$ as well as extracellular 
Table 1 Partial listing of molecules contributing to RGC axon guidance

\begin{tabular}{|c|c|c|c|c|c|c|}
\hline Guidance family & Mode of action & $\begin{array}{l}\text { Reported effect } \\
\text { on RGC axons }\end{array}$ & $\begin{array}{l}\text { Location in } \\
\text { developing visual } \\
\text { system }\end{array}$ & Remarks & Known receptors & $\begin{array}{l}\text { Selected } \\
\text { references }\end{array}$ \\
\hline Netrins & Secreted & Attractive & $\begin{array}{l}\text { Optic disc, optic } \\
\text { nerve }\end{array}$ & Homology to laminin & DCC, UNC5 & 12 \\
\hline Semaphorins & $\begin{array}{l}\text { Secreted and } \\
\text { membrane } \\
\text { bound }\end{array}$ & Inhibitory? & Retina? & $\begin{array}{l}\text { Large family (>20 members) semaphorin } \\
\text { domain }\end{array}$ & $\begin{array}{l}\text { Neuropilins } \\
\text { plexins }\end{array}$ & 28,29 \\
\hline Slits & Secreted & Inhibitory & $\begin{array}{l}\text { Retina, optic nerve, } \\
\text { optic chiasm, optic } \\
\text { tract }\end{array}$ & Form boundaries for RGC axons & Robos & $\begin{array}{l}20,21 \\
22\end{array}$ \\
\hline Ephrins & $\begin{array}{l}\text { Secreted and } \\
\text { membrane } \\
\text { bound }\end{array}$ & Inhibitory & $\begin{array}{l}\text { Retina, superior } \\
\text { colliculus }\end{array}$ & $\begin{array}{l}\text { Two subclasses: ephrin-A and ephrin-B form } \\
\text { gradients in retina and tectum }\end{array}$ & $\begin{array}{l}\text { EphA receptors } \\
\text { EphB receptors }\end{array}$ & 34,35 \\
\hline EphB proteins & $\begin{array}{l}\text { Membrane } \\
\text { bound }\end{array}$ & Inhibitory & Retina & "Reverse" signalling through ephrins & Ephrin B proteins & 39,40 \\
\hline L1 & $\begin{array}{l}\text { Membrane } \\
\text { bound }\end{array}$ & Attractive & $\begin{array}{l}\text { Expressed on RGC } \\
\text { axons }\end{array}$ & $\begin{array}{l}\text { Ig superfamily member maintains RGC axon } \\
\text { fasiculation }\end{array}$ & $\begin{array}{l}\text { Homophilic } \\
\text { binding }\end{array}$ & $7,8,60$ \\
\hline Laminin & $\begin{array}{l}\text { Extracellular } \\
\text { matrix }\end{array}$ & $\begin{array}{l}\text { Growth } \\
\text { promoting }\end{array}$ & Retina & $\begin{array}{l}\text { Commonly used as substrate for RGC axon } \\
\text { growth in vitro }\end{array}$ & Integrins & 61,62 \\
\hline Tenascin & $\begin{array}{l}\text { Extracellular } \\
\text { matrix }\end{array}$ & Inhibitory & Optic nerve & Expression begins after embryogenesis & Unknown & 55 \\
\hline $\begin{array}{l}\text { Chondroitin } \\
\text { sulphate }\end{array}$ & $\begin{array}{l}\text { Extracellular } \\
\text { matrix }\end{array}$ & Inhibitory & Retina & Inhibitory ring in outer retina & Unknown & 13,14 \\
\hline
\end{tabular}

matrix molecules like tenascin. ${ }^{55}$ Much like inhibitory axon guidance molecules, several of these proteins trigger growth cone collapse. This observation suggests that results from studies of the molecular basis of axonal pathfinding during development may to some degree be applicable to regeneration therapies in the clinical setting. Further weight is lent to this argument by the recent findings that axon guidance molecules important during development reappear in the setting of CNS injury. For instance, the inhibitory axon guidance molecule Sema3A is found in scar tissues following spinal cord injury, and is hypothesised to have a role in preventing CNS axon regeneration across the site of injury ${ }^{56}{ }^{57}$ (reviewed in Pasterkamp and Verhaagen ${ }^{58}$ ). In the visual system, members of the ephrin family that mediate the development of the retinocollicular map continue to be expressed in the adult superior colliculus after optic tract injury. ${ }^{59}$ This finding raises the prospect that sufficient molecular information may be present in the adult to reconstitute a functional retinal map in CNS targets. An implication of these findings is that it would be useful to examine whether the failure of adult retinal axon regeneration is in part due to the re-expression of inhibitory axon guidance molecules during the injury response. Important questions to be addressed include the cellular origin of these inhibitory molecules, whether these inhibitory molecules affect adult retinal axons, and whether strategies effective in changing embryonic retinal axon responses to specific guidance molecules will also work in adult axons. To answer these questions a systematic characterisation of the pathfinding ability of adult regenerating retinal axons will be required. With this information in hand, it may be possible in the future to formulate regeneration strategies based on an understanding of adult retinal axon pathfinding at the molecular level.

\section{NOTE ADDED AT PROOF STAGE}

Since submission of this review, the transmembrane semaphorin Sema5A has been implicated in mouse optic nerve development. ${ }^{63}$

\section{Authors' affiliations}

S F Oster, D W Sretavan, Departments of Ophthalmology and Physiology, Medical Scientist Training Program, Biomedical Sciences Program, Neuroscience Program, University of California San Francisco, San Francisco, CA, USA

\section{REFERENCES}

1 Suter DM, Forscher P. An emerging link between cytoskeletal dynamics and cell adhesion molecules in growth cone guidance. Curr Opin Neurobiol 1998;8:106-16.

2 Song $\mathbf{H}$, Ming G, He Z, et al. Conversion of neuronal growth cone responses from repulsion to attraction by cyclic nucleotides. Science 1998;281:1515-8.

3 Song HJ, Poo MM. Signal transduction underlying growth cone guidance by diffusible factors. Curr Opin Neurobiol 1999;9:355-63.

4 Tessier-Lavigne M, Goodman CS. The molecular biology of axon guidance. Science 1996;274:1123-33.

5 Yu TW, Bargmann Cl. Dynamic regulation of axon guidance. Nat Neurosci 2001;4(Suppl): 1 169-76.

6 Burden-Gulley SM, Pendergast M, Lemmon V. The role of cell adhesion molecule L1 in axonal extension, growth cone motility, and signal transduction. Cell Tissue Res 1997;290:415-22.

7 Brittis PA, Lemmon V, Rutishauser U, et al. Unique changes of ganglion cell growth cone behavior following cell adhesion molecule perturbations: a time-lapse study of the living retina. Mol Cell Neurosci 1995;6:433-49.

8 Ott H, Bastmeyer M, Stuermer CA. Neurolin, the goldfish homolog of DM-GRASP, is involved in retinal axon pathfinding to the optic disk. J Neurosci 1998;18:3363-72.

9 Kennedy TE, Serafini T, de la Torre JR, et al. Netrins are diffusible chemotropic factors for commissural axons in the embryonic spinal cord. Cell 1994;78:425-35.

10 Serafini T, Kennedy TE, Galko M, et al. The netrins define a family of axon outgrowth-promoting proteins homologous to $C$ elegans UNC-6. Cell 1994;78:409-24.

11 Serafini T, Colamarino SA, Leonardo ED, et al. Netrin-1 is required for commissural axon guidance in the developing vertebrate nervous system. Cell 1996:87:1001-14.

12 Deiner MS, Kennedy TE, Fazeli A, et al. Netrin-1 and DCC mediate axon guidance locally at the optic disc: loss of function leads to optic nerve hypoplasia. Neuron 1997;19:575-89.

13 Brittis PA, Canning DR, Silver J. Chondroitin sulfate as a regulator of neuronal patterning in the retina. Science 1992;255:733-6.

14 Snow DM, Letourneau PC. Neurite outgrowth on a step gradient of chondroitin sulfate proteoglycan (CS-PG). I Neurobiol 1992;23:322-36. 15 Kidd T, Bland KS, Goodman CS. Slit is the midline repellent for the robo receptor in Drosophila. Cell 1999;96:785-94.

16 Simpson JH, Bland KS, Fetter RD, et al. Short-range and long-range guidance by Slit and its Robo receptors: a combinatorial code of Robo receptors controls lateral position.. Cell 2000;103:1019-32. 
$17 \mathrm{Hu} \mathrm{H}$. Chemorepulsion of neuronal migration by Slit2 in the developing mammalian forebrain. Neuron 1999;23:703-11

18 Wang KH, Brose K, Arnott D, et al. Biochemical purification of a mammalian slit protein as a positive regulator of sensory axon elongation and branching. Cell 1999;96:771-84.

19 Wu W, Wong K, Chen J, et al. Directional guidance of neuronal migration in the olfactory system by the protein Slit. Nature 1999;400:331-6.

20 Brose K, Tessier-Lavigne M. Slit proteins: key regulators of axon guidance, axonal branching, and cell migration. Curr Opin Neurobiol 2000;10:95-102.

21 Plump AS, Erksine L, Sabatier C, et al. Slit1 and Slit2 cooperate to prevent premature midline crossing of retinal axons in the mouse visual system. Neuron 2002;33:219-32.

22 Niclou SP, Jia L, Raper JA. Slit2 is a repellent for retinal ganglion cell axons. J Neurosci 2000;20:4962-74.

23 Erskine L, Williams SE, Brose K, et al. Retinal ganglion cell axon guidance in the mouse optic chiasm: expression and function of robos and slits. J Neurosci 2000;20:4975-82.

24 Ringstedt T, Braisted JE, Brose K, et al. Slit inhibition of retinal axon growth and its role in retinal axon pathfinding and innervation patterns in the diencephalon. J Neurosci 2000;20:4983-91.

25 Nakamura F, Kalb RG, Strittmatter SM. Molecular basis of semaphorin-mediated axon guidance. J Neurobiol 2000;44:219-29.

26 Raper JA. Semaphorins and their receptors in vertebrates and invertebrates. Curr Opin Neurobiol 2000;10:88-94.

27 Luo Y, Raible D, Raper JA. Collapsin: a protein in brain that induces the collapse and paralysis of neuronal growth cones. Cell 1993;75:217-27

28 Campbell DS, Regan AG, Lopez JS, et al. Semaphorin 3A elicits stage-dependent collapse, turning, and branching in Xenopus retinal growth cones. J Neurosci 2001;21:8538-47.

29 Encinas JA, Kikuchi K, Chedotal A, et al. Cloning, expression, and genetic mapping of Sema W, a member of the semaphorin family. Proc Natl Acad Sci USA 1999:96:2491-6.

30 Marin O, Yaron A, Bagri A, et al. Sorting of striatal and cortical interneurons regulated by semaphorin- neuropilin interactions. Science 2001;293:872-5.

31 Taniguchi $M$, Yuasa S, Fukisawa $H$, et al. Disruption of semaphorin III/D gene causes severe abnormality in peripheral nerve projection. Neuron 1997:19:519-30.

32 Bonhoeffer F, Huf J. Position-dependent properties of retinal axons and their growth cones. Nature 1985;315:409-10

33 O'Leary DD, Wilkinson DG. Eph receptors and ephrins in neural development. Curr Opin Neurobiol 1999;9:65-73.

34 Wilkinson DG, Topographic mapping: organising by repulsion and competition? Curr Biol 2000;10:447-51.

35 Feldheim DA, Vanderhaeghen P, hansen M, et al. Topographic guidance labels in a sensory projection to the forebrain. Neuron 1998;21:1303-13.

36 Colamarino SA, Tessier-Lavigne $M$. The axonal chemoattractant netrin-1 is also a chemorepellent for trochlear motor axons. Cell 1995;81:621-9.

37 Hedgecock EM, Culotti JG, Hall DH. The unc-5, unc-6, and unc-40 genes guide circumferential migrations of pioneer axons and mesodermal cells on the epidermis in C. elegans. Neuron 1990;4:61-85.

38 Holland SJ, Gale NW, Mbamalu, G, et al. Bidirectional signalling through the EPH-family receptor Nuk and its transmembrane ligands. Nature 1996;383:722-5.

39 Birgbauer E, Oster, SF, Severin CG, et al. Retinal axon growth cones respond to EphB extracellular domains as inhibitory axon guidance cues. Development 2001;128:3041-8.

40 Birgbauer E, Cowan CA, Sretavan DW, et al. Kinase independent function of EphB receptors in retinal axon pathfinding to the optic disc from dorsal but not ventral retina. Development 2000;1 27: 1231-41.

41 Winberg ML, Mitchell KJ, Goodman CS. Genetic analysis of the mechanisms controlling target selection: complementary and combinatorial functions of netrins, semaphorins, and IgCAMs. Cell 1998;93:581-91.
42 Ming GL, Song HJ, Berninger B, et al. cAMP-dependent growth cone guidance by netrin-1. Neuron 1997;19:1225-35.

43 Hopker VH, Shewan D, Tessier-Lavigne M, et al. Growth-cone attraction to netrin-1 is converted to repulsion by laminin-1. Nature 1999:401:69-73.

44 Stein E, Tessier-Lavigne M. Hierarchical organization of guidance receptors: silencing of netrin attraction by slit through a Robo/DCC receptor complex. Science 2001;291:1928-38.

45 Zou Y, Stoeckli E, Chen H, et al. Squeezing axons out of the gray matter: a role for slit and semaphorin proteins from midline and ventral spinal cord. Cell 2000;102:363-75.

46 Kolodkin AL, Matthes DJ, Goodman CS. The semaphorin genes encode a family of transmembrane and secreted growth cone guidance molecules. Cell 1993;75:1389-99.

47 Kolodkin AL, Matthes DJ, O'Connor TP, et al. Fasciclin IV: sequence, expression, and function during growth cone guidance in the grasshopper embryo. Neuron 1992;9:831-45.

48 Mitchell KJ, Doyle JL, Serafini T, et al. Genetic analysis of netrin genes in Drosophila: netrins guide CNS commissural axons and peripheral motor axons. Neuron 1996;17:203-15.

49 Brose K, Bland KS, Wang KH, et al. Slit proteins bind Robo receptors and have an evolutionarily conserved role in repulsive axon guidance. Cell 1999:96:795-806.

50 Deiner MS, and Sretavan DW. Altered midline axon pathways and ectopic neurons in the developing hypothalamus of netrin-1- and DCC-deficient mice. J Neurosci 1999;19:9900-12.

51 Skarf B, Hoyt CS. Optic nerve hypoplasia in children. Association with anomalies of the endocrine and CNS. Arch Ophthalmol 1984; 102:62-7.

52 Hashimoto $M$, Ohtsuka K, Nakagawa T, et al. Topless optic disk syndrome without maternal diabetes mellitus. Am J Ophthalmol 1999; 128:111-2.

53 Brittis PA, Flanagan JG. Nogo domains and a Nogo receptor: implications for axon regeneration. Neuron 2001;30:11-4.

54 Shen YJ, DeBellard ME, Salzer JL, et al. Myelin-associated glycoprotein in myelin and expressed by Schwann cells inhibits axonal regeneration and branching. Mol Cell Neurosci 1998;12:79-91.

55 Becker T, Anliker B, Becker CG, et al. Tenascin-R inhibits regrowth of optic fibers in vitro and persists in the optic nerve of mice after injury. Glia 2000;29:330-46.

56 Pasterkamp RJ, Anderson PN, Verhaagen J. Peripheral nerve injury fails to induce growth of lesioned ascending dorsal column axons into spinal cord scar tissue expressing the axon repellent Semaphorin3A. Eur J Neurosci 2001;13:457-71.

57 Pasterkamp RJ, Giger RJ, Ruitenberg M, et al. Expression of the gene encoding the chemorepellent semaphorin III is induced in the fibroblast component of neural scar tissue formed following injuries of adult but not neonatal CNS. Mol Cell Neurosci 1999;13:143-66.

58 Pasterkamp RJ, Verhaagen J. Emerging roles for semaphorins in neural regeneration. Brain Res Rev 2001;35:36-54.

59 Bahr M, Wizenmann A. Retinal ganglion cell axons recognize specific guidance cues present in the deafferented adult rat superior colliculus. $J$ Neurosci 1996;16:5106-16.

60 Crossin KL, Krushel LA. Cellular signaling by neural cell adhesion molecules of the immunoglobulin superfamily. Dev Dyn 2000;218:260-79

61 Colognato H, Yurchenco PD. Form and function: the laminin family of heterotrimers. Dev Dyn 2000;218:213-34.

62 Reichardt LF, Bossy B, de Curtis I, et al. Adhesive interactions that regulate development of the retina and primary visual projection. Cold Spring Harb Symp Quant Biol 1992;57:419-29.

63 Oster SF, Bodeker MO, He F, et al. Invariant Sema5A inhibition serves an ensheathing function during optic nerve development. Development $2003 ; 130: 775-84$ 